\title{
Correction to: Deciphering post-infarct inflammation: Should it heal, would it hurt?
}

\author{
Matthias Nahrendorf, PhD, ${ }^{\mathrm{a}}$ Antonio Abbate, $\mathrm{MD}, \mathrm{PhD},{ }^{\mathrm{b}}$ and Jagat Narula, MD, \\ PhD, MACC, MASNC \\ a Massachusetts General Hospital, Harvard Medicial School, Boston, MA \\ b VCU Pauley Heart Center, Virginia Commonwealth University, Richmond, VA \\ c Mount Sinai Morningside Hospital, Icahn School of Medicine at Mount Sinai, New York, NY
}

doi: $10.1007 / \mathrm{s} 12350-020-02090-8$

\section{CORRECTION TO:}

\section{JOURNAL OF NUCLEAR CARDIOLOGY} HTTPS://DOI.ORG/10.1007/S1 2350-020-020

53-Z

In the original version of the editorial, a wrong figure was used. The original article has been corrected.
Publisher's Note Springer Nature remains neutral with regard to jurisdictional claims in published maps and institutional affiliations.

The original article can be found online at https://doi.org/10.1007/ s12350-020-02053-z.

Reprint requests: Jagat Narula, MD, PhD, MACC, MASNC, Mount

Sinai Morningside Hospital, Icahn School of Medicine at Mount

Sinai, 421 W. 113th Street, Suite 130, New York, NY 10025;

narula@mountsinai.org

J Nucl Cardiol 2020;27:1384.

$1071-3581 / \$ 34.00$

Copyright (C) 2020 American Society of Nuclear Cardiology. 